of sodium is much lower in dilute solutions than has been thought to be the case, ranging from $1.5^{8}$ to $28.43 \%$ at a dilution of Ioo liters per gram molectie in the silicates which vary respectively in their $\mathrm{Na}_{2} \mathrm{O}: \mathrm{SiO}_{2}$ ratio of from $i: 4$ to $I: x$.

4. The findings of earlier investigators, that the metasilicate, $\mathrm{Na}_{2} \mathrm{SiO}_{3}$, was most completely hydrolyzed, and that as more silica was added to the molectle the degree of hydrolysis decreased, have been confirmed.

PITTSBURG, $P_{A}$.

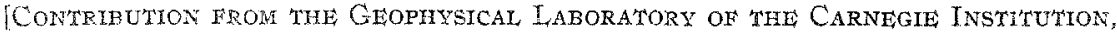
OF WASmington.]

\title{
THE SYSTEM CUPRIC OXIDE, CUPROUS OXIDE, OXYGEN.
}

Ey F. Hastings SMYTH and Howard S. RoBerts.

Received October 16,1920。

\section{Previous Work on the System.}

The system cupric oxide, cuprous oxide, oxygen has been studied by 1. Wöler. ${ }^{1}$ The results of this investigation led to the conclusion that cupric and cuprous oxides form a continuous series of solid solutions. That is, if cupric oxide was heated in vacuo to a temperature such that it began to lose oxygen according to the reaction

$$
{ }_{4} \mathrm{CuO}(\mathrm{s}) \longleftrightarrow{ }_{2} \mathrm{Cu}_{2} \mathrm{O}(\mathrm{s})+\mathrm{O}_{2},
$$

this action was not accompanied by the formation of a second solid phase. The 2-component system remained in 2 phases, solid solution of the 2 oxides and gas, until all oxygen required by the reaction had been removed. and pure cuprous oxide remained. If the temperature of the charge was held constant and successive quantities of oxygen were removed, the equilibrium pressure varied continuously from that of pure cupric oxide to that of pure cuprous oxide. The true dissociation pressure of cuptic oxide was not determined directly by Wöhler, since some oxygen was always lost from the charge used, in order to fill the apparatus with oxygen at the pressure corresponding to the initial temperature of each experiment. The volume of the apparatus used is not given, nor are the stccessive quantities of oxygen removed in any experiment indicated and it is impossible to follow the composition of the solid phase. All the results are therefore qualitative. However, using the same apparatus, with varying charges and with removal of varying quantities of oxygen, different equilibrium pressures of oxygen were obtained at identical temperatures. There are given in Table I a few of the results, which are typical.

1L. Wöhler. 2. Elecktrochem, I2, 78I (ron6). 
TABXE I.

Wöhler's Data on Dissociation of Cupric Oxide.

Charge: Pure cupric oxide.

Temperature, ${ }^{\circ} \mathrm{C}$.
rooo
1020
1040
1084

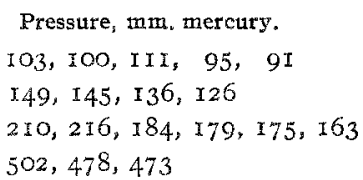

A dissociation pressure-temperature curve obtained by using an initial mixed charge of $50 \%$ each of cuprous and cupric oxides, gave values unifornly lower than those obtained with an initial charge of pure cupric oxide, as shown in Table II. It was remarked by Wöhler that the charges, when removed from the apparatus, appeared to be homogeneous, though apparently a microscopic examination was not made.

TABLE II.

Wöhler's Data on Dissociation of Mixed Copper Oxides.

Temperature, ${ }^{\circ} \mathrm{C}$.

Pressure, mx. mercury,

$\begin{array}{rrr}960 & 3 \mathrm{I} & 5 \mathrm{I} \\ 1000 & 65 & 103 \\ 1030 & 108 & 177 \\ 1060 & 164 & 290\end{array}$

On the other hand, Foote and Smith ${ }^{1}$ obtained identical values for dissociation pressures, at various temperatures, of mixed charges of the 2 oxides in various proportions, which would indicate that solid solution does not occur.

\section{Purpose of the Present Investigation.}

The original purpose of the present work was to confirm, if possible, the results of Wöhler and to determine accurately the compositions of solid solutions of cupric and cuprous oxides corresponding to a series of pressures at a number of different temperatures, and to find the true equilibrium pressure of the reaction

$$
{ }_{4} \mathrm{CuO}(\mathrm{s}) \rightleftarrows{ }_{2} \mathrm{Cu}_{2} \mathrm{O}(\mathrm{s} \text { solution in } \mathrm{CuO})+\mathrm{O}_{2}(\mathrm{~g})
$$

with as nearly pure cupric oxide as possible.

It may be said at the outset, however, that the results of our experiments are not in agreement with those obtained by Wöhler, and that we have been nuable to prove the existence of any solid solutions of cuprous oxide in cupric oxide. When cupric oxide loses oxygen, a second solid phase appears at once. This consists of small ruby-colored crystals, readily seen. under a sinall glass, throughout the cooled charge of partially dissociated oxide, These are probably crystals of pure cuprous oxide, although our results do not entirely exclude the possibility of their contaiting a very small quantity of cupric oxide. However, it will develop

${ }_{1}$ Foote and Snith, This Journal, 30, I344 (1908). 
that the cupric oxide content of these crystals must be very small, if it exists at all. The composition of this second solid phase certainly does not vary sufficiently to make its effect felt in the general form of the dissociation pressure-temperature curve of cupric oxide, and in the present paper this phase is treated as pure cuprous oxide.

This investigation then resolved itself into a determination of the equilibrium constant of the reaction

$$
{ }_{4} \mathrm{CuO}(\mathrm{s}) \longleftrightarrow{ }_{2} \mathrm{Cu}_{2} \mathrm{O}(\mathrm{s})+\mathrm{O}_{2}(\mathrm{~g})-\Delta \mathrm{H}_{1}
$$

both throughout the temperature range where cupric and cuprous oxides remain solids, and also above the melting point of the entectic of the 2 oxides where the possible reactions are:

and

$$
{ }_{4} \mathrm{CuO}(\mathrm{s}) \rightleftarrows{ }_{2} \mathrm{Cu}_{2} \mathrm{O}(1 \text { solution in } \mathrm{CuO})+\mathrm{O}_{2}(\mathrm{~g})-\Delta H_{2}
$$

$$
{ }_{4} \mathrm{CuO}\left(1 \text { solution in } \mathrm{Cu}_{2} \mathrm{O}\right) \rightleftarrows{ }_{2} \mathrm{Cu}_{2} \mathrm{O}(\mathrm{s})+\mathrm{O}_{2}(\mathrm{~g})-\Delta \mathrm{H}_{3}
$$

$\Delta H_{1}, \Delta H_{2}$, and $\Delta H_{3}$ are the heats absorbed in the several reactions.

\section{Theoretical Discussion.}

The form of the melting diagram for mixtures of cuprous and cupric oxides at various temperatures under equilibrium pressures of oxygen gas is not known. Excluding the possibility of the formation of compounds, and of solid solutions between the 2 oxides, we may assume, for the purpose of this discussion, a diagram like that of Fig. I.

If a large quantity of cupric oxide be heated in a system of small volume to a temperature, $t$, above the eutectic point, the pressure being

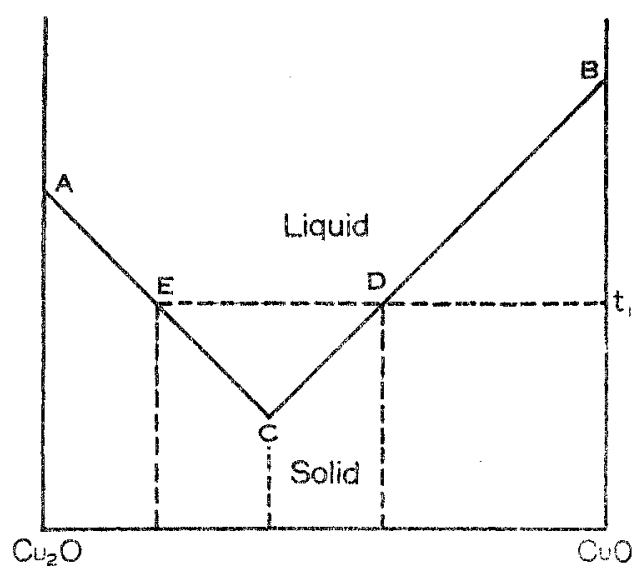

Fig. I,-Arbitrary melting-point diagram, system; $\mathrm{CuO}, \mathrm{Cu}_{2} \mathrm{O}$. allowed to vary, the composition of the melt formed after dissociation has begun will be given by the point D (Fig. I), and the 3 phases present will be solid cupric oxide, a liquid solution of cuprous oxide in cupric oxide, and oxygen gas. That is, Reaction II will take place. With increasing temperature the proportion of cupric oxide to cuprous oxide in the liquid in general becomes larger.

On the other hand, if a large amount of oxygen be allowed to escape from the charge of cupric oxide or if the original charge consist largely of cuprous oxide, the composition of the melt at the temperature $t$, will be given by the point $E_{\text {on }}$ the diagram, and the 3 phases present will then be solid cuprous 
oxide, liquid solution of cupric oxide in cuprous oxide, and oxygen gas. Reaction III will take place and with increasing temperature the proportion of cuprous oxide in the melt becomes greater.

At the eutectic point $\mathrm{C}, 4$ phases exist at equilibrium, both solid oxides, liquid, and oxygen gas. Since the system is one of 2 components, the point $\mathrm{C}$ is invariant. On the other hand, along the lines $\mathrm{CA}$ and $\mathrm{CB}$ the system is monovariant, and the temperature may be adjusted at will if the oxygen pressure is allowed to vary.

At any temperature below the eutectic point Reaction I takes place, and the system at equilibrium consists of 3 phases, solid cupric and cuprous oxides and oxygen gas. This system is also monovariant.

The pressure-temperature curves for the monovariant Reactions I, II and III can be followed by means of the Clapeyron equation

$$
\frac{\mathrm{d} p}{\mathrm{~d} T}=\frac{\Delta H}{T \Delta V} .
$$

Since both $\Delta H$ and $\Delta V$ can in general be divided into a number of more fundamental effects, we may write

$$
\frac{\mathrm{d} p}{\mathrm{~d} T}=\frac{\Delta H_{1}+\Delta H^{\prime}}{\Delta V_{\mathrm{g}}+\Delta V^{\prime}} \cdot \frac{\mathrm{r}}{T},
$$

where $\Delta H_{1}$ is the heat of dissociation, $i . e$, the heat absorbed in Reaction I at constant pressure, and $\Delta H^{\prime}$ is the summation of all other heat effects for the particular Reactions I, II, III; $V_{\mathrm{g}}$ is the volume of one mol of oxygen gas under equilibrium conditions; $\Delta V^{\prime}$ the combined change in the volume of the solid or liquid phases.

As has already been stated, however, no compound has been found between cupric oxide and cuprous oxide, and also for Reaction I, at least, solid solution of small amounts of cuprous oxide in cupric oxide does not occur. Also we have found no evidence of solid solution of cupric oxide in cuprous oxide.

\section{Reaction I. ${ }_{4} \mathrm{CuO}(\mathrm{s}) \rightleftarrows 2 \mathrm{Cu}_{2} \mathrm{O}(\mathrm{s})-\mathrm{O}_{2}(\mathrm{~g})$.}

As neither fusion nor solidification takes place in this reaction, we shall, for the moment, assume that $\Delta H_{1}$ is constant over the range investigated. Then, ignoring the possibility of solid solution and changes iin specific heats of the reacting substances, $\Delta H^{\prime}$ is negligible. Since the pressure along this curve has remained less than $400 \mathrm{~mm}$., we may also neglect $\Delta V^{\prime}$ in comparison with $V_{\mathrm{g}}$. Making these assumptions, Equation 2 becomes

$$
\frac{\mathrm{d} p}{\mathrm{~d} t}=\frac{\Delta H_{1}}{T V_{\mathrm{g}}} .
$$

Replacing $V_{g}$ by $R T / p$ and integrating, we obtain

$$
m p=-\frac{\Delta H_{1}}{R T}+\text { Const. }
$$


the usual integrated form of the van't Hoff equation. The fact that within the limits of experimental error, our data satisfy Equation 4 (cf. Fig. 7), shows that the assumptions made above are justified.

Reaction II. ${ }_{4} \mathrm{CuO}$ (s) $\rightleftarrows{ }_{2} \mathrm{Cu}_{2} \mathrm{O}$ (1 solution in $\left.\mathrm{CuO}\right)+\mathrm{O}_{2}(\mathrm{~g})$.

Here dissociation is accompanied by fusion, not only of 2 mols of cuprous oxide formed, but of additional cupric oxide in order to form a liquid sufficiently rich in cupric oxide to be in equilibrium with the solid phase. As the temperature is raised, the melt requires increasingly more cupric oxide per mol of cuprous oxide (cf. Fig. I, line CB). Consequently $\Delta H^{\prime}$, which includes heats of fusion and dilution must increase. For the same reason $\Delta V^{\prime}$ is negligible only at points at a distance from the melting point of pure cupric oxide, and at low pressures. For the lower temperatures, Equation 2 becomes

$$
\frac{\mathrm{d} p}{\mathrm{~d} T}=\frac{\Delta H_{1}+\Delta H^{\prime}}{T V_{\mathrm{g}}}
$$

As $\Delta H^{\prime}$ is positive, the slope of this curve is always greater than that of the extrapolation of the curve in the case of Reaction I, and it increases with rising temperature.

As we pass along the line $\mathrm{CB}$ (Fig. $\mathrm{I}$ ) and approach the melting point of cupric oxide, continuously larger quantities of cupric oxide must melt to dissolve the 2 mols of cuprous oxide formed in Reaction II. At the limit which is the melting point of pure cupric oxide, we can consider that an infinite amount of cuptic oxide must melt to dissolve the cuprous oxide formed. As this point is approached, the solid and liquid phases approach the same composition and $\Delta H^{\prime}$ and $\Delta V^{\prime}$ increase without limit. $\Delta H_{1}$ and $V_{g}$ can then be neglected and we obtain as the limit is approached

$$
\frac{\mathrm{d} p}{\mathrm{~d} T}=\frac{\Delta H^{\prime}}{T \Delta V^{\prime}} .
$$

Now since $\Delta H^{\prime}$ is the heat required to melt a very large, though definite quantity of cupric oxide, and $\Delta V^{\prime}$ is the volume change of the same quantity of oxide on melting, Equation 6 is the equation of the pressure-temperature curve for the condensed system $\mathrm{CuO}(\mathrm{s}), \mathrm{CuO}(1)$. The dissociation-pressure curve then becomes tangent to the melting. point pressure curve for pure cupric oxide at the temperature corresponding to the dissociation pressure of pure cupric oxide at its melting point.

Reaction III. ${ }_{4} \mathrm{CuO}\left(1\right.$ solution in $\left.\mathrm{Cu}_{2} \mathrm{O}\right) \longleftrightarrow{ }_{2} \mathrm{Cu}_{2} \mathrm{O}(\mathrm{s})+\mathrm{O}_{2}(\mathrm{~g})$.

Here dissociation is accompanied by solidification; consequently $\Delta H^{\prime}$ is negative, and, since $\Delta V^{\prime}$ can again be neglected except near the melting point of cuprous oxide, the slope of the curve $d p / d T$ must be less than that of the extrapolation of the curve in the case of Reaction I. Again $\Delta H^{\prime}$ increases, numerically, without limit as the temperature is 
raised (cf. Fig. I, line CA). Consequently the algebraic sum $\Delta H_{1}+\Delta H^{\prime}$ becomes less until the point is reached where $\Delta H_{1}+\Delta H^{\prime}=0$, which is a maximum on the pressure-temperature curve. This point, it shotld be noted, may or may not lie on a stabie part of the curve, because at the point C (Fig. I) the amount of liquid cuprous oxide necessary to dissolve 4 mols of cupric oxide may already be large, and sufficient to give to $\Delta H^{\prime}$ a numerical value greater than that of $\Delta H_{1}$. As soon as the value of $\Delta H^{\prime}$ does become greater than that of $\Delta H_{1}$, the slope of $\mathrm{d} p / \mathrm{d} T$ of the curve becomes negative.

For most substances, fusion is accompanied by an increase in volume. $\Delta V^{\prime}$ is therefore probably negative and as its numerical value increases also without limit on approaching the melting point of cuprous oxide, the algebraic sum $V_{\mathrm{G}}+\Delta V^{\prime}$ must at some point become zero. Here the slope of the curve is negatively infinite.

Finally, as we approach the melting point of cuprous oxide, the slope of the curve is again given by Equation 6, but in this case both numerator and denominator of the second member of the equation have negative values. As in the case of Reaction II, therefore, the end of the curve has a positive slope and is tangent at the melting point of cuprous oxide to the pressure-temperature curve for the condensed system $\mathrm{Cu}_{2} \mathrm{O}(\mathrm{s}), \mathrm{Cu}_{2} \mathrm{O}(1)$, at a temperature which corresponds to the dissociation pressure of pure cupric oxide at its melting point.

The value of $\mathrm{d} p / \mathrm{d} T$ for the system $\mathrm{Cu}_{2} \mathrm{O}(\mathrm{s}),\left[\mathrm{CuO}, \mathrm{Cu}_{2} \mathrm{O}\right](1), \mathrm{O}_{2}(\mathrm{~g})$ therefore has at first a positive value, passes through zero, and becomes negative. Its negative value increases to infinity and toward the very end of the curve the slope again becomes positive. This end of the curve also may not lie in a region in which the system is stable, because as the pressure is lowered, the cuprous oxide present may itself start to dissociate with the appearance of a possible new phase, liquid or solid, and giving a system whose equilibrium pressure again increases with rising temperature. However, the dissociation pressure of cuprous oxide in the neighborhood of its melting point $\left(1210^{\circ}\right)$ is known to be less than $5 \mathrm{~mm}$. of mercury. ${ }^{1}$

The principal fact which develops from this discussion is that the oxygen equilibrium pressure for Reaction III in general falls with rising temperature, with the exception of the small regions at the beginning of the curve where the numerical value of $\Delta H^{\prime}$ is less than that of $\Delta H_{1}$ and at the end of the curve where both total heat and volume changes for Reaction III are negative.

It remains to be noted that since the eutectic point is a quadruple point for the system $\mathrm{CuO}(\mathrm{s}), \mathrm{Cu}_{2} \mathrm{O}(\mathrm{s}), \mathrm{O}_{2}(\mathrm{~g}),\left[\mathrm{Cu}_{2} \mathrm{O}, \mathrm{CuO}\right](1)$, all three of the above dissociation-pressure curves intersect at that point.

${ }^{2}$ Slade and Farrow, Proc. Roy. Soc. [A,] 87, 524 (I912). 
In the above discussion, heats of dilution of one liquid oxide in the other have been considered as negligible as compared with the heats of fusion involved.

\section{Apparatus and Materials.}

(a) Apparatus for Moderate Pressures. The apparatus used is shown diagrammatically in Fig. 2, and consisted essentially of a reaction chamber of silica glass, $50 \mathrm{~cm}$. long and $12 \mathrm{~mm}$. internal diameter, closed at the lower end and attached through a ground joint to a glass cap $20 \mathrm{~cm}$.

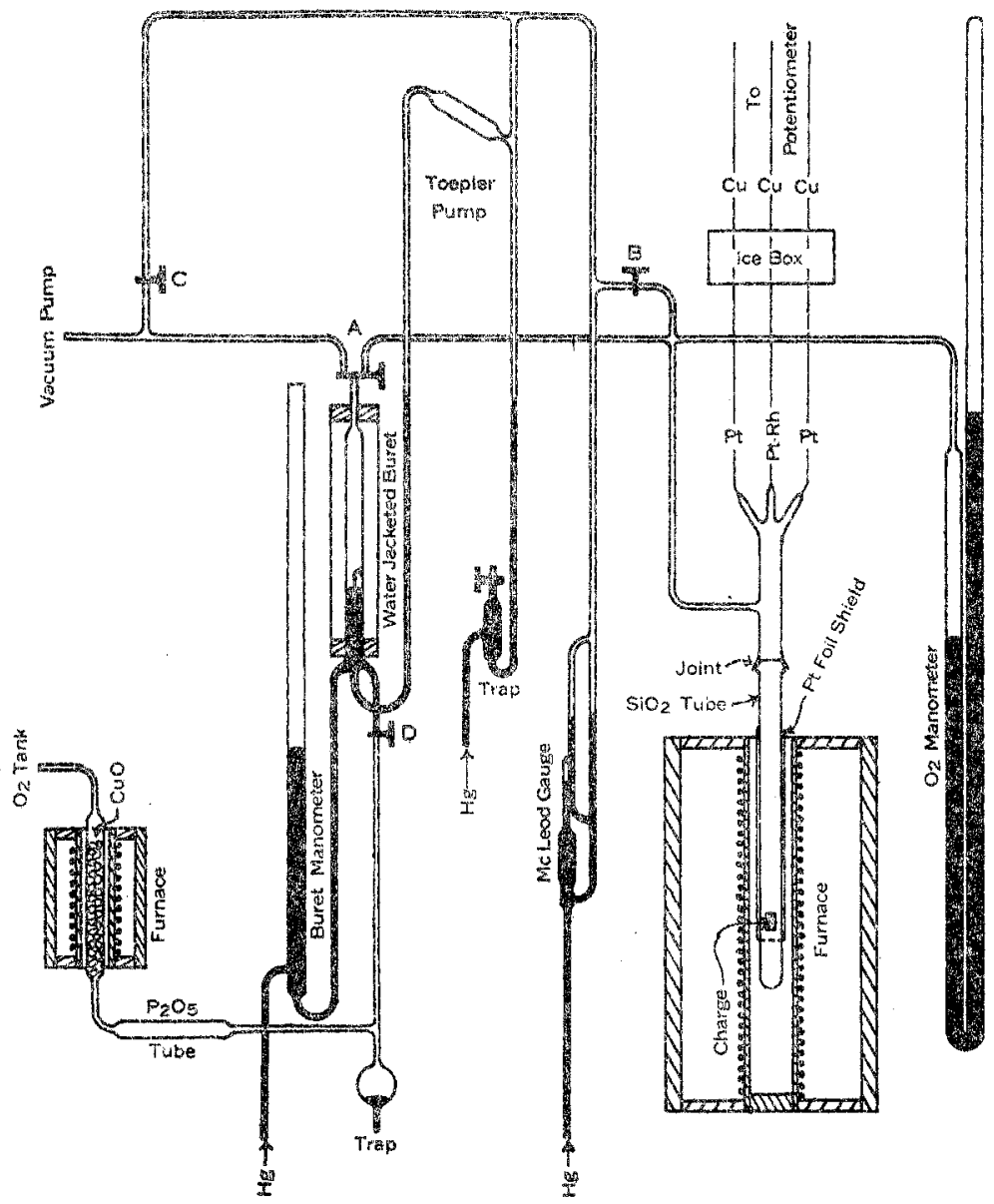

Fig. 2.-Apparatus used for measurements of pressutes less than 3 atmospheres.

long and of the same diameter as the tube itself through which were sealed the thermo-element connections. The manometer used for measuring equilibritun pressures was that which has already been used and described by Day and Clement' in gas thermometric work.

1 Day and Clement, Am. J. Sci., 24, 415 (1908). 
A water-jacketted buret, of constant and known volume, was arranged so that quantities of oxygen either admitted or withdrawn from the system could be accurately measured. This was accomplished by adjusting a mercury column in the buret, so that the meniscus came to a glass point shown in the figure, and reading the level of the other meniscus in the buret manometer by means of a telescope cathetometer, which could be read to $0.1 \mathrm{~mm}$. Fresh oxygen was adrnitted to the buret through the cock $\mathrm{D}$, from a cylinder of electrolytic oxygen. On the other hand, oxygen from the system was withdrawn by means of a Toepler pump, the capillary of which discharged into the bottom of the buret. When pressures in the apparatus were sufficiently high, oxygen could be withdrawn directly.into the buret through the 2-way Cock A, but with low pressures, readily measurable amounts of oxygen had to be pumped out.

The McLeod gage in the system served. simply to determine when evacuation was complete, or to test for leaks.

The furnace used had a platinum wound alundum tube, $45 \mathrm{~cm}$. long, and of $3 \mathrm{~cm}$. internal diameter, insulated with magnesia. It was arranged on a sliding frame, so that it could be readily lowered away from the reaction tube, to allow the walls of the latter to be quickly cooled by spraying them with water. Exploration of this furnace with a thermoelement showed a range of at least $5 \mathrm{~mm}$. through which the temperature within the charge did not vary more than $0.1^{\circ}$ at $1100^{\circ}$. The height of the furnace in each experiment was adjusted so that this constant temperature region surrounded the charge of oxides.

Details of the way in which the charge was suspended are shown in Fig. 3. A
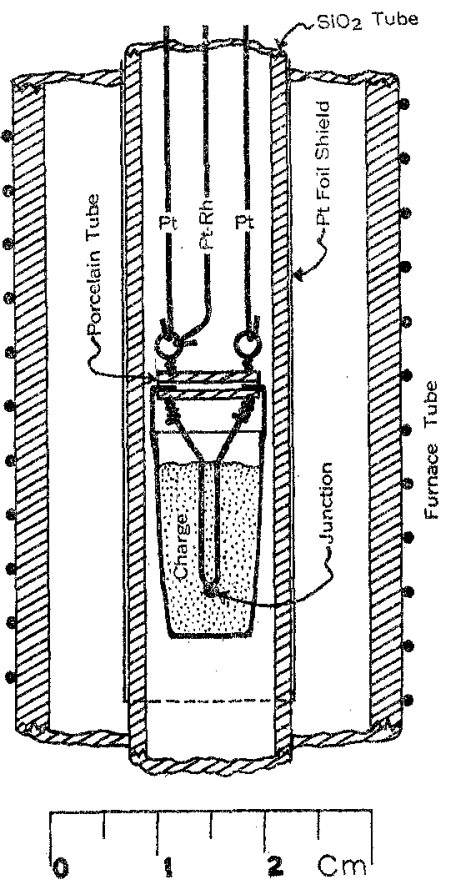

ig. 3.-Section through low-pressure furnace showing method of supporting charge and arrangement of thermoelements. small platinum crucible, about $10 \mathrm{~mm}$. in diameter, was used to hold the charge. The crucible was lined with a thin coating of sintered magnesia, ${ }^{1}$ and the thermoelement tip was also protected in this way. These magnesia coatings were not acted on by the copper oxides,

${ }_{1}$ Magnesia coating prepared by applying a paste made from finely ground magnesia moistened with water saturated with magnesium nitrate. After painting this paste on the walls of the crucible it was slowly dried and then ignited by raising its temperature slowly to about $1600^{\circ}$. 
as long as the latter remained solid. Above the fusion temperatures, however, no lining was found which would not react with the charge, and the platinum crucible was used unlined. The liberation of oxygen, however, due to absorption of copper by the platinum, is slow, compared to the rate at which dissociation equilibrium is accomplished, and is not a disturbing factor in the presence of cuprous oxide.

The thermoelement used for measuring the temperature of the charge was within the charge as shown. The crucible was suspended by platinum hooks from a small piece of capillary porcelain tube (Fig. 3). This piece of tube also carried and insulated the thermoelement tip, which was renewed before each experiment. Another thermoelement junction placed immediately above the crucible outside the charge, was used in certain cases to follow absorption or evolution of heat by the charge itself,

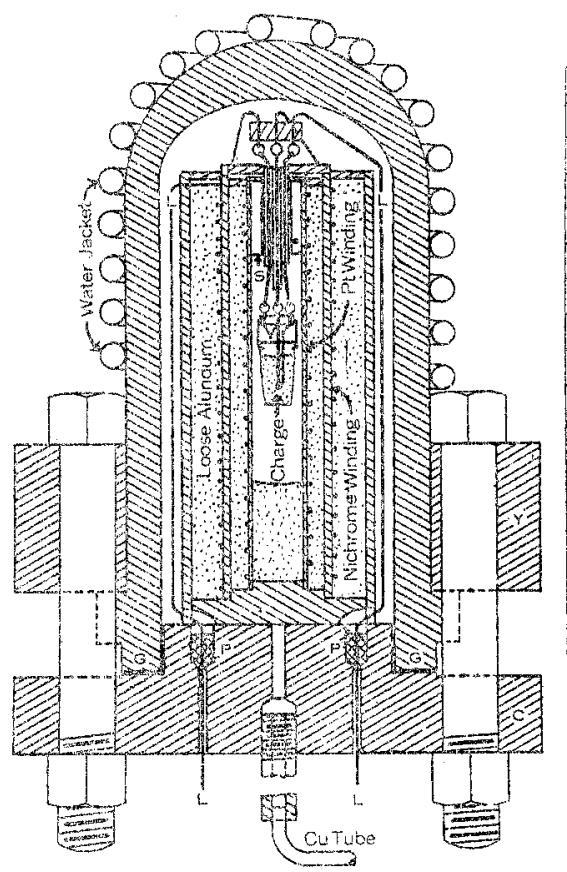
using the differential method. ${ }^{1}$ The platioum and platinum-10\% rhodium alloy wires used for these elements were calibrated at the gold point $\left(1062.6^{\circ}\right)$. Thermoelement potentials were read with a Wolff potentiometer. The whole potentiometer system was shielded, ${ }^{2}$ a platinum foil shield being placed around the quartz reaction tube.

(b) Apparatus for High Pressures. - For pressures greater than $2000 \mathrm{~mm}$. of mercury the furnace shown in Fig. 4 was used. This was a small, wire-wound, cascade furnace built into an inverted bronze autoclave. The furnace proper was made with alundum tubing and alundum end rings, and a fireclay base.

Fig. 4.-Section through bomb-furnace for L,oose, granular, alundum was measuring pressures higher than 3 atmospheres.

used for insulation rather than magnesia because of the tendency of the latter to be blown out of the furnace when the gas pressure was released.

As in the case of the furnace used for low pressures, 2 thermocouples of platinum-platinrhodium were employed, one located in the middle

${ }^{2}$ C. N. Fenner, Am. J. Sci., 36, 361 (1913).

"W. P. White, "Leakage Prevention by Shielding," Thrs Jouranal, 36, 201 I (I9T4). 
of the charge itself and the other directly above the crucible. From these, the 3 thermocouple lead wires passed through porcelain capillaries to the top of the furnace where they were hooked over loops supported by the porcelain block B. A circular platinum diaphragm, S, was supported by a platinum sleeve around the porcelain tubes, which in turn was connected by a wire, not shown in the figure, to the potentiometer shield. The electrical leads, $L$, of which there were 6 , passed through holes in the cover of the autoclave, made gas-tight with soapstone plugs, $\mathrm{P}$, which were spread into the holes under sufficiently heavy pressure to upset the soapstone and stretch the surrounding bronze. ${ }^{1}$

Connection to the oxygen tank and pressure gage was made through a fine copper tube. All the joints in this line were soft soldered to prevent leaks.

The autoclave was cooled by circulating water through a jacket of copper tubing, soldered in place, and through holes drilled in the cover $\mathrm{C}$ and the yoke $\mathrm{Y}$. These holes are not shown in the figure.

Packing was provided at $G$ in the form of a lead gasket. This was compressed by means of 6 bolts. The whole was supported on a bracket beneath the cover, so that the bottom was accessible.

Since organic matter in the presence of oxygen under pressure is apt to explode, the furnace was carefully heated all over to redness, and the inside of the autoclave washed with carbon tetrachloride before it was used.

The oxygen pressures in this furnace were read on a Bourdon gage reading up to Iooo pounds per square inch and previously calibrated in this laboratory.

Electric current for both furnaces was supplied by storage batteries, which gave practically an unvarying potential and allowed very constant temperature regulation.

(c) Volume of Moderate Pressure System.-To avoid calculations involving temperature gradients in the gas contained in the apparatus between the heated furnace portion and the tubes at room temperature, the quantity of oxygen contained by the apparatus at various furnace temperatures was determined empirically.

With the furnace in place, and heated to a definite temperature, but with no charge in the apparatus, a measured quantity of oxygen was admitted from the buret, and the resulting pressure in the apparatus was read on the manometer. Assuming that the temperature of the entire quantity of admitted gas remained at room temperature, and that the ordinary pressure-volume relations still applied to the partially heated system, what may be called an "apparent volume" of the apparatus was calculated. From this value the oxygen contained in the system at other

${ }^{1}$ A modification of the seal used by Adams, Williamson and Johnston, Trus JourNAL, 4T, 18 (1919). 
pressures, the furnace temperature being kept constant, could be closely estimated.

Furthermore, the change in the value of this "apparent volume" was not great with a variation of furnace temperature between $700^{\circ}$ and $1100^{\circ}$, being $165.3 \mathrm{cc}$. at $1065^{\circ}$ and $172.6 \mathrm{cc}$. at $725^{\circ}$. The assumption is therefore further made here that this value is a linear function of the temperature of the furnace within this range. The actual volume of the apparatus at the uniform temperature of $22^{\circ}$ was $201.7 \mathrm{cc}$.

The quantities of oxygen lost by a charge when heated in the previously evacuated apparatus, are calculated in the following experiments from the values obtained in the manner predicted above. It will develop later that these values need not be very accurately known.

(d) Preparation of Copper Oxides.-The cupric oxide used in all experiments was prepared from c. P. "copper drops cooled in hydrogen" of the lot previously used as a melting-point standard in gas thermometric work in this laboratory. ${ }^{1}$ The metallic copper was heated in an electric muffle furnace at low red heat for several days, in the presence of gentle air circulation. The resulting mass containing cupric and cuprous oxides and unoxidized copper was then removed from the furnace and ground in an agate mortar. That portion of the fines which passed a 50-mesh sieve was again heated in a porcelain boat in a tube combus tion furnace at about $800^{\circ}$ in a current of dry air for 3 or 4 days and until the boat and its contents ceased to gain weight during a heating period of 24 hours. When examined under a microscope, ${ }^{2}$ the resulting cupric oxide appeared to be homogeneous and to contain opaque black particles only. It is a significant fact that until such time as the oxide ceased to gain weight while heated in the air current, the microscope always disclosed small ruby-colored crystals of cuprous oxide scattered throughout the mass as a separate solid phase. A sufficient quantity of oxide for all the following work was thus prepared, ground in an agate mortar to pass a 200-mesh sieve, mixed thoroughly, and kept as a stock, to assure uniform material for each experiment.

Cuprous oxide was prepared from the cupric oxide described above, by heating a portion of it in a porcelain boat at $900^{\circ}$, and pumping off oxygen at $5 \mathrm{~mm}$. pressure, until the material ceased to lose in weight and until microscopic examination showed no black cupric oxide present as a separate phase.

(e) Oxygen.-The oxygen gas used was from a cylinder of compressed electrolytic oxygen, analysis of which showed the presence of less than $0.1 \%$ of gas which could not be absorbed in dilute ammonia solution in

${ }^{1}$ E. T. Allen, in paper by Day and Clement, Am. J. Sci., [4], 26, 456 (1908), finds $0.0083 \%$ total impurities in it.

"Microscope work by H. E. Merwin. 
the presence of metallic copper. It was freed from hydrogen by passing over heated cupric oxide and dried in a tube containing phosphorus pentoxide.

\section{Experimental Results. I. Absence of Solid Solutions and the Equil-} ibrium Pressures of the System $\mathrm{CuO}(\mathrm{s}), \mathrm{Cu}_{2} \mathrm{O}(\mathrm{s}), \mathrm{O}_{2}(\mathrm{~g})$.

Experiment 1.-A charge of pure cupric oxide was placed in the apparatus, and the system was pumped down to o.or mm. mercury pressure, with the charge and furnace tube heated to about $300^{\circ}$. The temperature was then raised to about $984^{\circ}$. The initial manometer pressure was read after equilibrium was reached. Successive quantities of oxygen were then removed. After each removal of oxygen the temperature was brought back to $984^{\circ}$ and the pressure was again recorded when it reached a constant value. Each recorded pressure reading was approached several times from temperatures both above and below $984^{\circ}$. The results are given in Table III. In Table III arrows after pressure values indi-

\section{TABI, TII.}

Dissociation Pressures of Cupric Oxide.

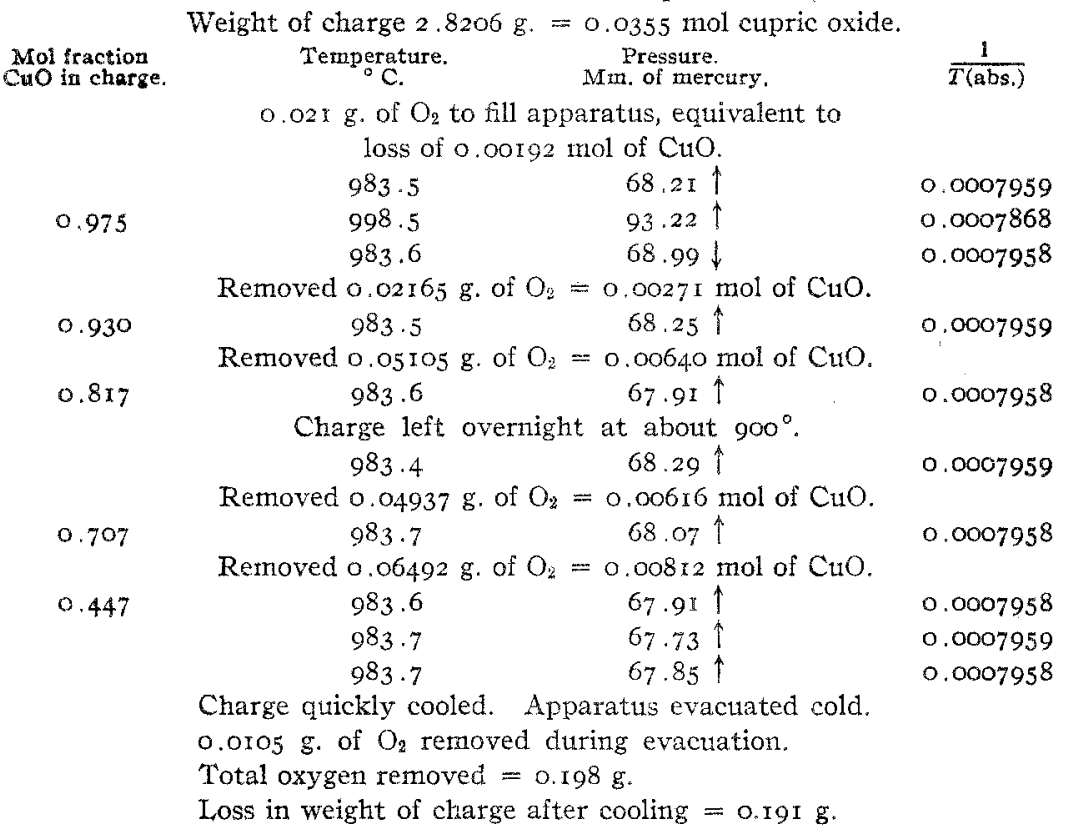

cate whether pressure was reached from above or below the equilibrium pressure. That is, an upward pointed arrow indicates that the recorded pressure was reached from a lower value, and by dissociation.

After the experiment the charge was quickly cooled and the crucible removed and weighed. The loss in weight (O.I9I g.) corresponds fairly closely to the calculated weight of oxygen removed during the experiments. 
It was not possible to quench the charge rapidly enough to avoid the absorption of some oxygen during cooling. The total quantity of oxygen available from $2.8206 \mathrm{~g}$. of cupric oxide, assuming the reaction: $4 \mathrm{CuO} \longrightarrow$ $2 \mathrm{Cu}_{2} \mathrm{O}+\mathrm{O}_{2}$, is $0.283 \mathrm{~g}$. From this we calculate that $69 \%$ by weight of cupric oxide was converted into ctuprous oxide during the experiment. Microscopic examination of the cooled charge showed it to be about $2 / 3$ converted into cuprous oxide which appeared as entirely distinct red crystals separate from the remaining black particles of cupric oxide. This result strongly indicates the absence of solid solutions at $984^{\circ}$. With the idea that high initial pressures (obtained by previous investigators) might. be due to the giving off of adsorbed nitrogen by the charge of cupric oxide under certain conditions, the following experiment was tried.

Experiment 2.-A charge of pure cupric oxide was placed in the apparatus and pumped to o.or $\mathrm{mm}$. pressure at room temperature. The charge was then treated as in Experiment $I$. The results are given in Table IV. During this experiment the behavior of the temperature of

TABLE IV,

Dissociation Pressures of Cupric Oxide.

Charge: $2.7822 \mathrm{~g}$ of cupric oxide.

Tamperature.

983.7

983.0

982.7

982.7

982.7

\section{Pressure.}

Mis. of mercury,
Behavior of temperature of eharge on ramoval of oxygen.

\section{Oxygen required to fill appatatus $=0.02 \mathrm{I} g \mathrm{~g}$.}

$8 \mathrm{I} .22$ 个

$77.3 \mathrm{I}$

75.88

Removed $0.001 \mathrm{I} \mathrm{g}$. of $\mathrm{O}_{2}$

$74.10 \%$

Removed $0.0597 \mathrm{~g}$. of $\mathrm{O}_{2}$. 7 I.08 †

Removed $0.0720 \mathrm{~g}$. of $\mathrm{O}_{\mathrm{g}}$

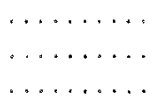

$\operatorname{Drop} 2^{\circ}$

Drop $3^{\circ}$

Drop $4^{\circ}$

Fumace cooled overnight to room temperature, Pressure dropped to zero. Gas completely re-absorbed.

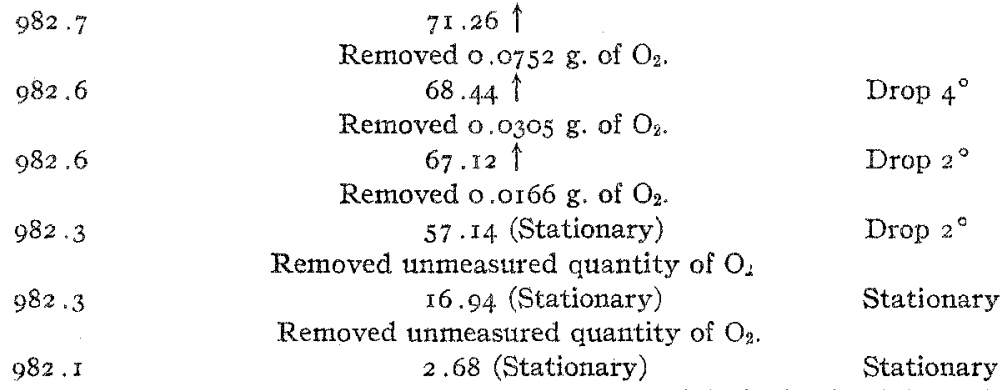

Last pressure rose about $0.2 \mathrm{~mm}$. in 30 minutes, possibly indicating initial dissociation of cuprous oxide.

Total oxygen removed to point where pressure did not react to temperature $=$ $0.276 \mathrm{~g}$.

Theoretical amount of oxygen required to give pute cuprous oxide $=0.280 \mathrm{~g}$. 
the charge during the removal of oxygen from the system was carefully watched. The slightest amount of dissociation was immediately noticeable by the temperature drop in the charge which it caused.

The above results show a continual decrease in the apparent equilibrium pressure of about $8 \mathrm{~mm}$. between the point at which the charge is practically pure cupric oxide and the point at which it is nearly converted into cuprous oxide.

After the removal of about $0.07 \mathrm{~g}$. of oxygen the equilibrium pressure fell about $5 \mathrm{~mm}$. and was practically unchanged by the further removal of $0.147 \mathrm{~g}$. On the further removal of $0.0305 \mathrm{~g}$. of oxygen, dissociation was nearly complete, cuprous oxide was present in excess, and the equilibrium pressure was adjusting itself very slowly.

Erom what we know of the effect on dissociation pressures of the formation of solid solutions, the pressure changes indicated in Table IV are hardly sufficiently great to be attributed to this cause. Sosman and Hostetter ${ }^{2}$ found that in the case of the solid solutions of ferroferric oxide in ferric oxide, the dissociation pressure dropped about $50 \%$ of its initial value at $1200^{\circ}$, while the ferrous oxide content of the charge increased from zero to $13 \%$. No such parallel behavior of the pressure can be noted in the present experiment where the initial pressure dropped only $6 \%$ of its original value on removal of less than $3 \%$ of the total available oxygen, and then remained practically unchanged until dissociation of the cupric oxide was complete.

As each quantity of oxygen was removed, the temperature of the charge dropped from $2^{\circ}$ to $4^{\circ}$, until the pressure became $57.14 \mathrm{~mm}$. This pressure was not sensitive to slight temperature changes, and further removal of oxygen gave a manometer reading of $16.94 \mathrm{~mm}$. without any effect ot the charge temperature due to further dissociation. This shows that when dissociation is complete, the equilibrium pressure drops abruptly, subsequent pressures being insensitive to temperature change, and removal of oxygei from the system causing no temperature reaction in the charge. The slightly high initial pressure, therefore, obtained in this experiment is probably due to the liberation of nitrogen adsorbed by the cupric oxide during cooling in air.

The following experiment shows that cupric oxide does retain adsorbed gas very tenaciously.

Experiment 3.--A charge of about $3 \mathrm{~g}$. of cupric oxide was heated slowly from room temperature, during which time the system was evacuated continuously by means of the diffusion pump. Readings of pressure and temperature are plotted against time in Fig. 5. The pressure curve ( $P$ in the figure) passes through a maximum at about $365^{\circ}$; an extrapolation of the right-hand portion of the curve reaches about 0.01

'Sosman and Hostetter, THis Journal, 38, 832 (1916). 
mm. at $365^{\circ}$ as shown by the dotted line. This is presumably about the pressure that would be developed by the cupric oxide if no gas were adsorbed by it at this temperature.

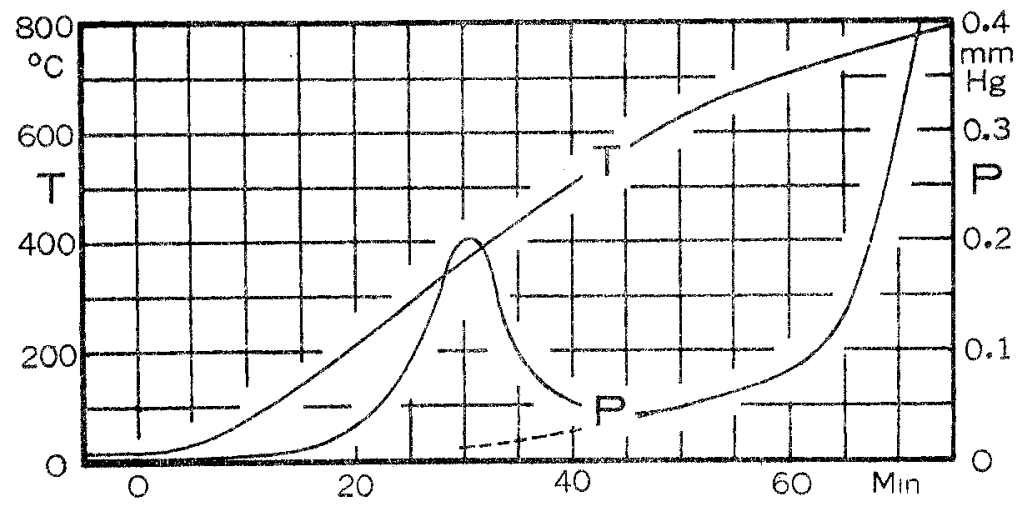

Fig. 5.-Pressure over charge during evacuation and simultaneous heating.

With another charge of cupric oxide the temperature was raised through a period of 40 minutes to $330^{\circ}$, running the pump continuousty as before. The furnace was then allowed to cool slowly, reaching $249^{\circ}$, when the pressure had fallen to $0.008 \mathrm{~mm}$. The furnace was lowered away from the reaction chamber and the system pumped down to o.oor $\mathrm{mm}$. at $50^{\circ}$ and shut off from the pump. The charge was then heated rapidly to $1055^{\circ}$ when a $300 \mathrm{cc}$. bulb, which had been connected to the system, was sealed off. After absorbing the oxygen in the bulb with an ammoniacal copper solution, $0.08 \mathrm{cc}$. of gas remained. This quantity of gas would have been sufficient to raise the pressure in the system by about $0.4 \mathrm{~mm}$. Thus even after pumping out a charge of cupric oxide at $330^{\circ}$ an appreciable amount of nitrogen remains which is driven out at higher temperatures. The results of this experiment, taken in conjunction with the high initial pressures of Expt. 2, indicate that when charges of cupric oxide, cooled in air, are heated in a closed system, misleading pressure values will almost certainly be obtained through the liberation of adsorbed nitrogen at high temperatures.

Experiment 4.-The equilibrium pressure of oxygen over practically pure cupric oxide was determined as follows. A charge of cupric oxide was pumped down at $200^{\circ}$. Oxygen was then run into the apparatus at a pressure of $228.65 \mathrm{~mm}$. and the temperature was raised to about $984^{\circ}$. Oxygen was then removed in very small amounts, until a pressure was reached where further withdrawal of oxygen caused a drop in the temperature of the charge, and a pressure adjustment took place. The results are given in Table $\mathrm{V}$. 
TABLE V.

Dissociation Pressures of Cupric Oxide.

Charge $2.2490 \mathrm{~g}$. of $\mathrm{Ct} O \mathrm{O}$.

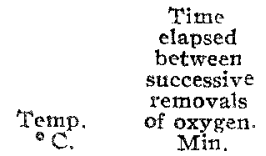

Pressure
ou
retnoval Time to
of
oxygench constant
Mm. of pressure.
mercury. Min.

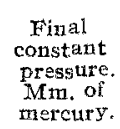

Tempera

ture

drop on

removal

mercury. Min.

Oxygen

$G$.

of oxygen.

… ․

Undet'd.

None

$983.3\left\{\begin{array}{l}983.2 \\ \mathrm{II}\end{array}\right.$

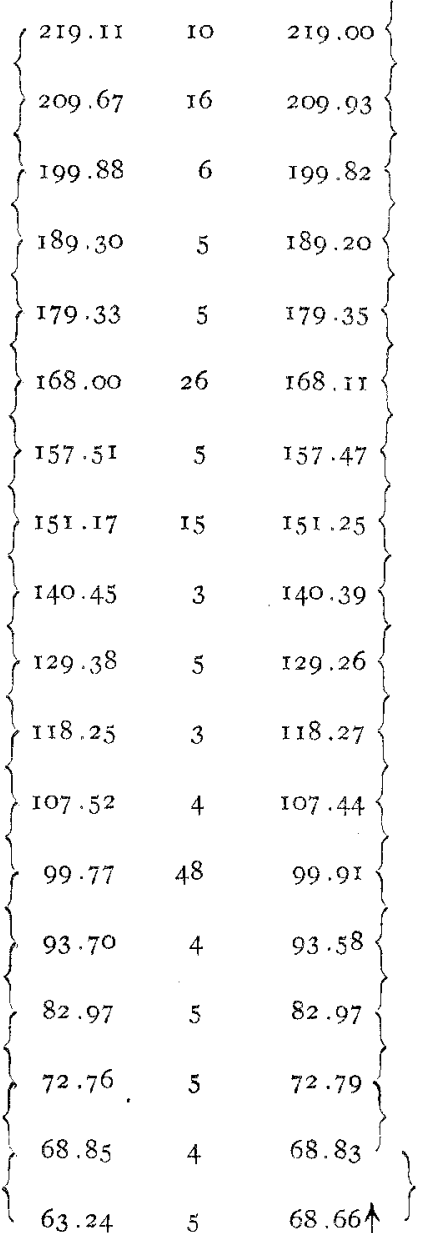

Indet'd

None

Lindet'd.

Undet'd.

Undet'd.

Undet'd.

Undet'd.

None
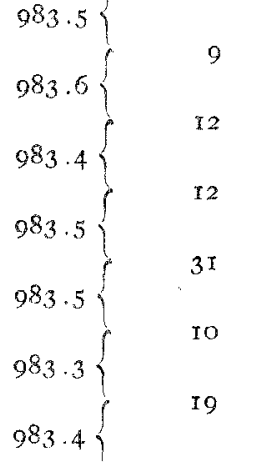

98

98.

08

98

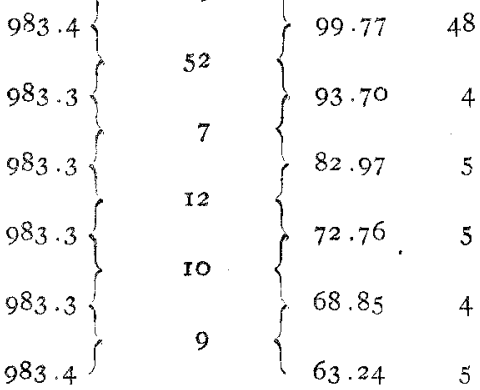

Undet'd.

Tndet'd.

Cndet'd.

None

None

None

None

None

None

None

Undet'd.

None

Undet'd.

None

Undet'd.

None

Undet'd.

None

Undet'd.

None

None

None

Undet'd.

Undet'd.

$8 \mathrm{~mm}$.

Left overnight at about $850^{\circ}$. Pressure dropped to $60.87 \mathrm{~mm}$. Temp. raised again to $983.6^{\circ}$ on following day, and held constant for 3 hrs.
$\left.\begin{array}{l}983.6 \\ 983.6 \\ 983.6\end{array}\right\}$
43 mits.
$\left\{\begin{array}{ccc}\cdots \cdots & 3 \text { hrs. } & 7 \pm .26 \uparrow \\ 62.96 & 4.0 \text { min. } & 70.26 \uparrow \\ 64.22 & 3 \mathrm{I} \text { min. } & 69.82 \uparrow\end{array}\right\}$
0.0152
$20 \mathrm{~m} . \mathrm{v}$.
0.0053
$17 \mathrm{~m} . \mathrm{v}$. 
An examination of this table shows that the charge did not begin to dissociate at $983.3^{\circ}$ until the pressure had dropped to $63.24 \mathrm{~mm}$. At this point an immediate drop of temperature was evident in the charge, and the pressure rose again to $68.66 \mathrm{~mm}$. when the temperature was restored to $983.3^{\circ}$. After leaving this charge for 17 hours at $850^{\circ}$, the pressure again rose to $71.26 \mathrm{~mm}$., after holding the temperature once more for 3 hours at $983.3^{\circ}$. Further removal of oxygen from the system did not effect a material change in the equilibrium pressure. These results agree with those obtained in Expt. I. That the final pressure (about $70 \mathrm{~mm}$. of mercury) was indeed the equilibrium pressure at $983.3^{\circ}$, was further demonstrated by twice again approaching this equilibrium temperature from 2 directions, with the results shown in Table VI.

TABLE VI.

Dissociation Pressures of Cupric Oxide. Charge: Same as that of Table V.

Temperature. ${ }^{\circ} \mathrm{C}$. $983 \cdot 5$

983.3
Pressure. Mm. of mercury.

$$
70.62 \bigvee
$$

Arrows indicate whether pressure was falling or rising at time of final reading.

The conclusion can safely be drawn that solid solutions of cuprous oxide in cupric oxide do not exist at $983^{\circ}$, and therefore probably at no temperature at which both oxides remain solid.

It remains, therefore, to determine the form of the oxygen equilibrium pressure curve for the reaction ${ }_{4} \mathrm{CuO} \rightleftarrows{ }_{2} \mathrm{Cu}_{2} \mathrm{O}+\mathrm{O}_{2}$.

As pointed out above, the curve will have 3 branches which will be treated separately: (I) when there are present oxygen gas and cupric and cuprous oxides as solid phases; (2) solid cupric oxide, liquid solution of cuprous oxide in cupric oxide, and oxygen gas; (3) solid cuprous oxide, liquid solution of cupric oxide in cuprous oxide, and oxygen gas.

One point on the first curve has been determined above in the search for solid solutions. At the conclusion of Expt. 4 the temperature of the charge was raised to determine 2 additional points, given in Table VII.

TABLE VII.

Dissociation Pressures of Cupric Oxide.

Charge: Same as that of Table IV.

Temperature. ${ }^{\circ} \mathrm{C}$.

1017.7

$1043 \cdot 3$

1043.2

$\mathrm{ro43.I}$
Pressure. Mm. of mereury.

$135.31 \uparrow$
$214.61 \uparrow$
214.61
$214.85 \uparrow$

The arrows again indicate whether pressure was approached from above or below the equilibrium point. Microscopic examination of the cooled charge removed after this experiment, showed the presence of considerable cuprous oxide.

Experiment 5.-A mixed charge of $0.7647 \mathrm{~g}$. of cuprous oxide and 
THE SXSTEM CUPRIC OXIDL, CUPROUS OXIDE, OXYGLN. 2599

$2.1616 \%$ of cupric oxide was heated to about $750^{\circ}$, the apparatus having been evacuated cold. The pressure rose to about $3.9 \mathrm{~mm}$. The charge was again cooled and the residual gas was pumped out to a pressure of $0.001 \mathrm{~mm}$. The charge was then heated to a series of temperatures. The results are given in 'Table VIII.

IABILE VIII.

Dissociation Pressures Obtained with a Charge of Mixed Oxides.

Charge: $0.7647 \mathrm{~g} \cdot \mathrm{C}_{12} \mathrm{O}$

2.1616 g. $\operatorname{CinO}$.

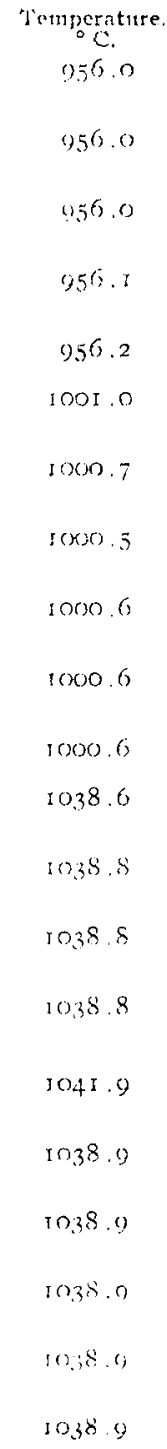

Pressure. Min. of inercury.

40.24

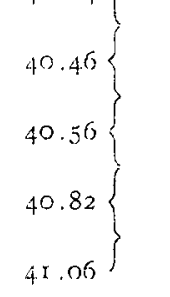

22

82

30

30

$97.07\} 14$

96.87

I 2

$0.0,0.5\{$

06.77

12

$\left.\begin{array}{l}96.77 \\ 96.79\end{array}\right\}$

7

4
2
12
7
9

$\left.\begin{array}{l}193.26 \\ 194.50 \\ 194.72 \\ 194.66\end{array}\right\}$

9

7

ro

Small ruantity of oxygen added.

of oxygen added.

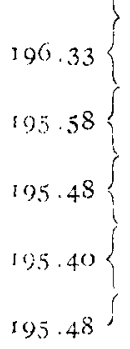

)

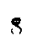




\begin{tabular}{|c|}
\hline $\begin{array}{c}\text { Temperature } \\
{ }^{\mathrm{C}} \text {. }\end{array}$ \\
\hline 2058.3 \\
\hline 1059.0 \\
\hline ro59.I \\
\hline I059. I \\
\hline $\operatorname{I059.2}$ \\
\hline ro59.2 \\
\hline $\operatorname{tos} 9 \cdot x$ \\
\hline ro59. I \\
\hline 106 I 6 \\
\hline 1060.0 \\
\hline 1059.2 \\
\hline $1059 . \mathrm{I}$ \\
\hline 1059.1 \\
\hline
\end{tabular}

TABLE VIII (continued).

Pressure.
Mm. of mercury.

236.097

I8

$277.47\{\quad 8$

277.55\{

278.53\{

3

8

6

3

Small quantity of oxygen added.

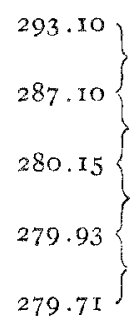

2

8

4

22

These results with a mixed charge are given in full in order to show that long periods were allowed at each temperature to approach equilibrium from both sides, and that the pressure changes rather slowly in the immediate neighborhood of the equilibrium point. The pressure is also very sensitive to exceedingly small temperature fluctuations, but Table VIII shows that the temperature was fairly well controlled.

Final equilibrinm pressures from the above experiments, with certain additional points determined in a similar manner, are tabulated in Table $\mathrm{IX}$, together with the reciprocals of the absolute temperatures, and the logarithms of the pressures.

The data of Table IX are plotted in Figs. 7 and 9. Previous results obtained by Foote and Smith are also shown, and our own values obtained with charges of mixed oxides are indicated by vertical lines.

The best curve which can be drawn through the points determined by the figures of Cols. 3 and 5 of Table IX, below the eutectic point, is a straight line (Fig. 7). All equilibrium points obtained, whether over pure cupric oxide, partially dissociated charges, or charges previously mixed, lie on this line within the limits of experimental error. This proves conclusively that the heat effect of Reaction I is substantially constant, 
and that solid solution between the 2 oxides cannot take place to an appreciable extent.

TABIE IX.

Equilibrium Pressures for the System $\mathrm{CuO}(\mathrm{s}), \mathrm{Cu}_{2} \mathrm{O}(\mathrm{s}), \mathrm{O}_{2}(\mathrm{~g})$. Summary of results of Experiments I to 4 , inclusive, with some additional points on the pressure-temperature curve

\begin{tabular}{|c|c|c|c|c|}
\hline $\begin{array}{l}\text { Temperature. } \\
{ }^{\circ} \mathrm{C} .\end{array}$ & $\begin{array}{l}\text { Temperature. } \\
\text { o Absolute. }\end{array}$ & $\frac{1}{T} \times 10^{3}$ & $\begin{array}{c}\text { Pressure, } \\
\text { Mm. of mercury. }\end{array}$ & $\log _{10} t$ \\
\hline 838.8 & IIII 8 & 0.8994 & 4.62 & 0.66464 \\
\hline 905.0 & $x \times 78.0$ & 0.8488 & 14.92 & I. 17377 \\
\hline 915.6 & 1188.6 & 0.8413 & 17.20 & I. 23553 \\
\hline 956.2 & 1229.2 & 0.8135 & $4 \cdot 1.06^{a}$ & I. 6 r 342 \\
\hline $956 . x$ & $1229 . \mathrm{I}$ & 0.8136 & 40.82 & I. 61087 \\
\hline 983.5 & 1256.5 & 0.7958 & 68.50 & I.83569 \\
\hline 983.3 & 1256.3 & 0.7959 & 70.50 & I. 84819 \\
\hline 983.5 & 1256.5 & 0.7958 & $70.60^{b}$ & I .84880 \\
\hline 1000.6 & 1273.6 & $0.785 \mathrm{I}$ & $96.77^{\alpha}$ & I. 98574 \\
\hline Ior 7.7 & 1290.7 & 0.7747 & $135.3 \mathrm{I}$ & 2.13133 \\
\hline 1038.8 & 1311.8 & 0.7623 & $195.00^{a}$ & 2.29003 \\
\hline 1043.1 & I3I6. I & 0.7598 & 214.85 & 2.33213 \\
\hline IO5O. I & $1332 . I$ & 0.7506 & $279.00^{a}$ & 2.44560 \\
\hline
\end{tabular}

"Charge of mixed oxides.

- Charge of pure cupric oxice (average value).

All other points obtained with partially dissociated charges.

6. Experimental Results. II: System $\mathrm{CuO}(\mathrm{s}),\left[\mathrm{CuO}_{2} \mathrm{Cu}_{2} \mathrm{O}\right](1), \mathrm{O}_{2}(\mathrm{~g})$.

In order to determine points on the equilibrium curve for this system, 2 methods were employed, both of which are somewhat subject to error due to the difficulty of temperature control and measurement when the charge starts to melt. These consisted first in heating a charge of pure cupric oxide in an excess pressure of oxygen to a given temperature and then removing oxygen slowly, as in Expt. 4 above, until the pressure returned to a constant value; and second, in heating pure cupric oxide in a high pressure of oxygen until dissociation took place. This last point was evident from the shape of the heating curve, because when dissociation began at a temperature above the eutectic point, fusion occurred at once.

The difficulty with both these methods lay in the fact that the temperature of the charge was always very erratic when fusion took place, because of the complicated changes which occurred. Between the eutectic point and the melting point of pure cupric oxide, fusion must be preceded by dissociation, and addition of heat causes a continuation of the process, which always seems to cause sudden local temperature changes throughout the charge. These were plainly registered by the thermoelement.

However, the sudden irregularities in temperature were themselves indications that dissociation and fusion were taking place, and smooth 
curves drawn through the irregulat parts of the actual heating curves obtained indicate the true temperature, it is thought, certainly within a degree. In Fig. 6 is shown a typical heating curve for a charge of cupric oxide under a pressure of $6700 \mathrm{~mm}$. of mercury. $117 \mathrm{I}^{\circ}$ is chosen as the corresponding temperature.

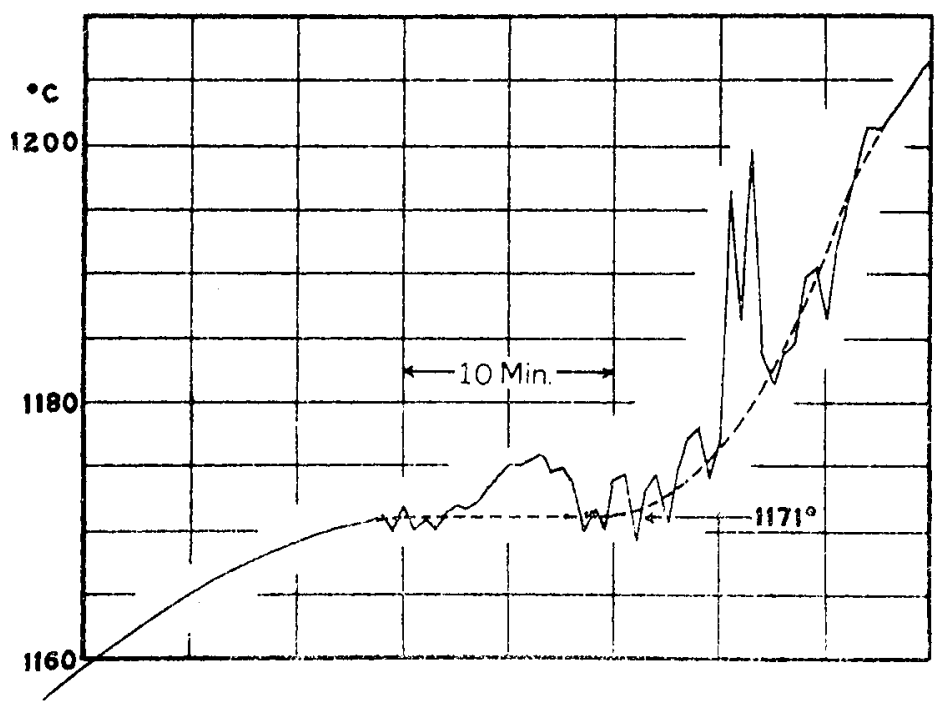

Fig. 6.-Typical time-temperature curve for melting cupric oxide with simultaneous dissociation.

Dissociation pressures up to $2000 \mathrm{~mm}$. were determined in the quartz. tube apparatus, the pressures being read on the mercury manometer. Higher pressures were determined in the bomb-furnace, and were read on the Bourdon gage. Results are given in Table $\mathrm{X}$.

\section{TABBLL: $\mathrm{X}$.}

Dissociation Pressures of Cupric Oxide. System $\mathrm{CuO}(\mathrm{s})-\mathrm{Cin}_{2} \mathrm{O} \cdot \mathrm{CuO}(1)-\mathrm{O}_{2}(\mathrm{~g})$.

$\begin{array}{cc}\text { Temperature. } & \frac{1}{\mathrm{~T}} \times 10^{3} \\ 108.3 .8 & 0.7370 \\ 1088.7 & 0.7345 \\ 1092.6 & 0.7322 \\ 1096.4 & 0.7302 \\ 1097.2 & 0.7298 \\ 1105.7 & 0.7253 \\ 1119.0 & 0.7184 \\ 1130.0 & 0.7128 \\ 1135.8 & 0.709 .4 \\ 1171.0 & 0.6925 \\ 1204.4 & 0.6760 \\ 1210.6 & 0.6740 \\ 1232.5 & 0.6642 \\ & \end{array}$

Pressure.
of mercury.
450
512
601
671
722
939
1258
1796
2020
6700
10090
21450
44700

Logio 0.

2.6 .532

2.709 .3

2.7789

2.8267

2.8585

2.9727

3.0997

3.234 .5

3.305 .3

$3.82 \mathrm{II}$

4.206 .3

4.3314

4.6503 
An examination of Table $\mathrm{X}$ shows a rapid rise of equilibrium pressure with temperature. But even at the highest pressure and temperature recorded, the melting point of pure cupric oxide without dissociation has not been reached. This is apparent from the logarithmic plot of these

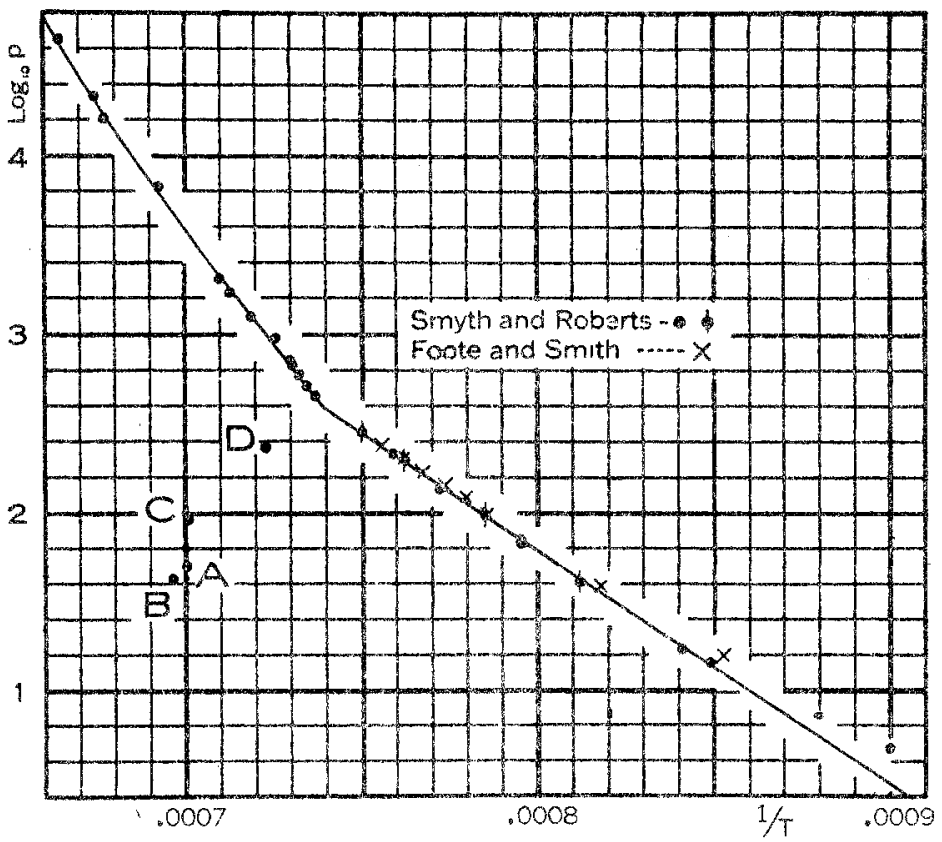

Fig. 7.--Plot of $\log _{10} p$ vs, I/T abs. for the dissociation of cupric oxide.

data (Fig. 7), in which the equilibrium curve does not yet show a tendency to become nearly vertical as would be predicted at the melting point of pure cupric oxide. It is shown more definitely by the fact that all the charges, when cooled, showed the presence of considerable cuprous oxide when examined under the microscope.

7. Experimental Results. III: System $\mathrm{Cu}_{2} \mathrm{O}(\mathrm{s}),\left[\mathrm{CuO}_{2} \mathrm{Cu}_{2} \mathrm{O}\right](1){ }_{2} \mathrm{O}_{2}(\mathrm{~g})$.

Charges of pure cuprous oxide were heated in the evacuated apparatus (Fig. 2) to temperatures above the eutectic point and oxygen was admitted in small quantities until it was absorbed by the charge and the pressure readily responded to slight temperature changes. That pressure adjustment appeared very rapid is shown on the accompanying plot (Fig. 8) in which pressures in mm. of mercury are plotted vertically and centigrade temperatures horizontally, the points representing readings 30 seconds apart, while the temperature of the charge was slowly raised and lowered. The ascending and descending curves lie very close to each other, indicating a slight lag of pressure adjustment behind the temperature but showing in a striking way how the pressure values vary in 
a manner the reverse of the temperature changes. Points lying in the center of pressure temperature loops thus obtained might be considered as representing equilibrium points. The two points $A$ and $B$ (Figs. 7 and 9) are shown with corresponding letters on the plots together with 2 other points obtained from independent experiments. 'This method of experimentation has, however, led to discordant results, and many points cetermined in this manner do not lie on any smooth curve which can be drawn through them and the eutectic point.

We hope later to show the cause of these variations, but for the present cannot show the true equilibrium values for this part of the systern. "These

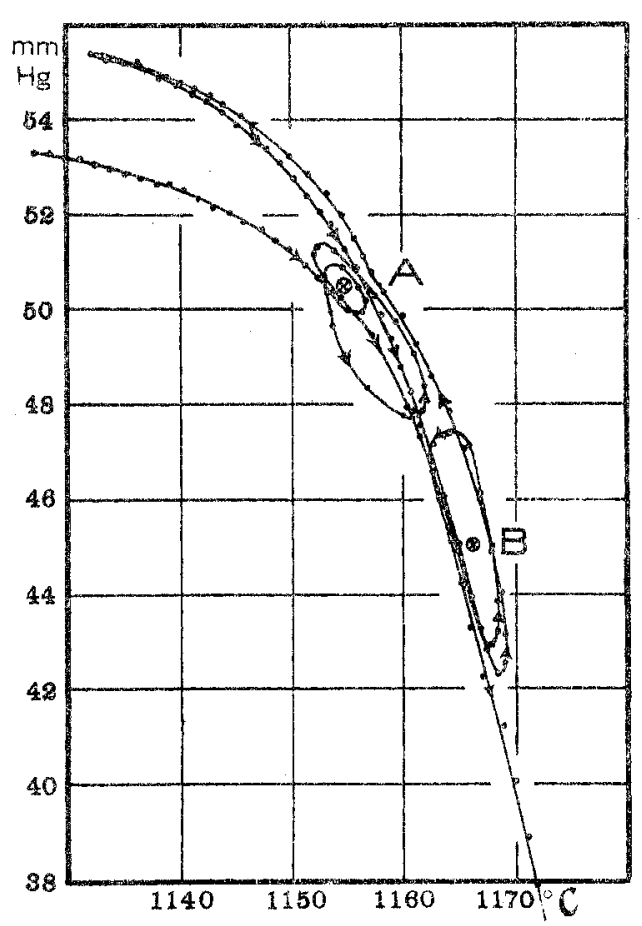

Fig. 8.-Showing behavior of pressure with temperature when the phases present are cuprous oxide, liquid mixture of cupric and cuprous oxides, and oxygen gas. preliminary results are here given as showing the main fact that the behavior of the pressure with the temperature is in accord with the prediction, and the general direction of the pressure temperature curve is indicated.

The Eutectic Point.-It has been found impractical to make a direct determination of the eutectic point, which is also the quadruple point of the system, by taking either heating or cooling curves on charges of mixed oxides. This is due to the fact that the temperature changes at this point become too erratic to interpret, even in the manner described above, in determining dissociation pressures at higher temperatures. The best value which can be given is therefore obtained by extrapolating the curves drawn through the accurately determined points to their intersection, which gives for the eutectic point a value of $390 \mathrm{~mm}$. pressure and $1080.2^{\circ}$ (Fig. 7). This point is also a point on the curve for the system, $\mathrm{Cu}_{2} \mathrm{O}(\mathrm{s}),\left[\mathrm{Cu}_{2} \mathrm{O}, \mathrm{CuO}\right](1), \mathrm{O}_{2}(\mathrm{~g})$.

Values of pressures in millimeters of mercury at temperature intervals of $20^{\circ}$, as taken from the logarithmic plot (Fig. 7), are given in Table XI. 
THE SYSTEM CUPRIC OXIDE, CUPROUS OXIDE, OXYGEN. 2605

TABLE XI.

Oxygen equilibrium pressures for the systems:

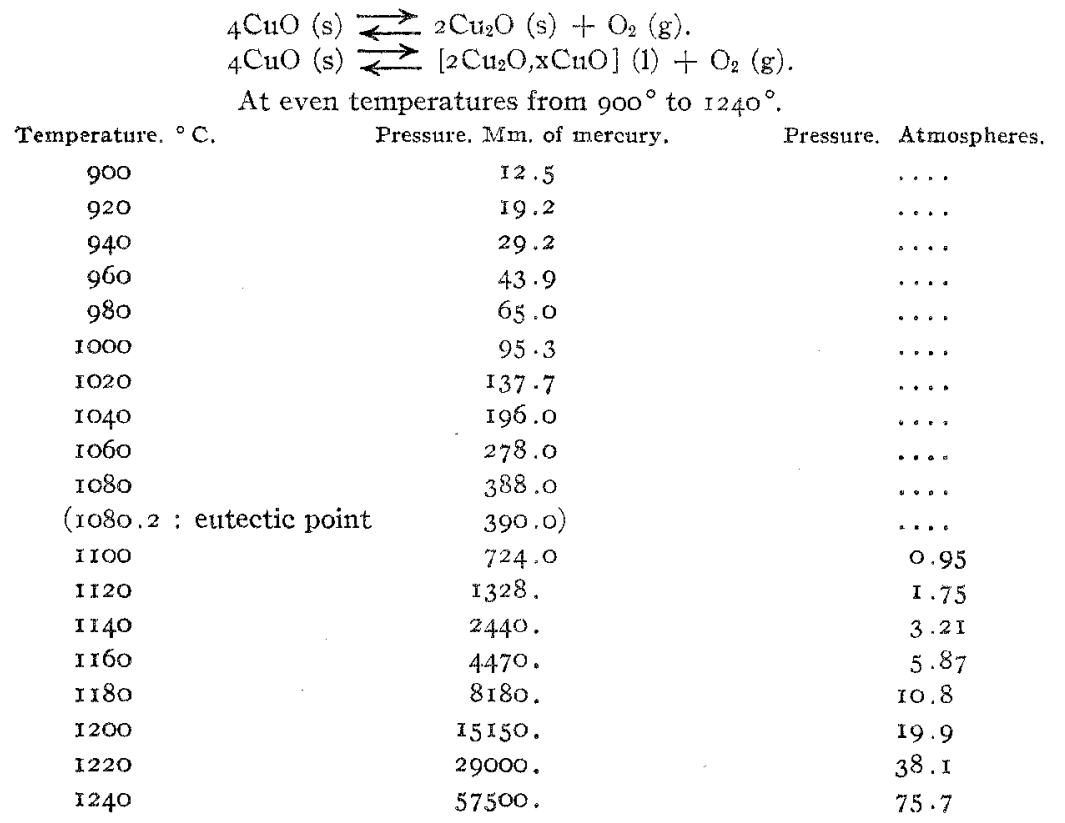

Fig. 9 shows the curve which the points of Table XI determine up to a pressure of $2000 \mathrm{~mm}$, together with the points experimentally found over this same pressure range.

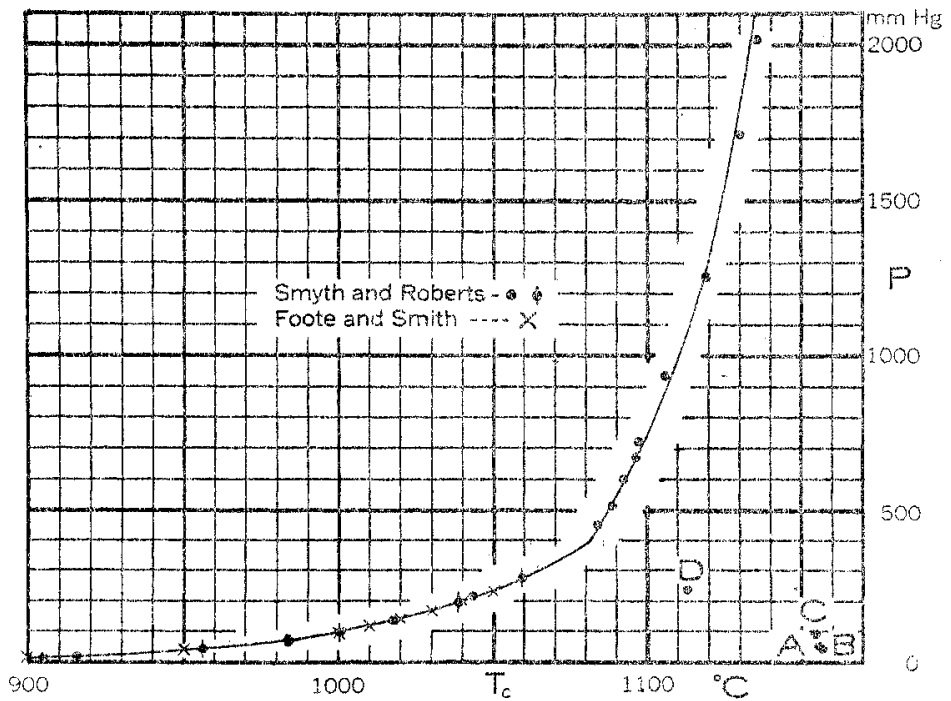

Fig. 9.-Dissociation pressure curve of cupric oxide. 


\section{Calculation of Energy Changes.}

Over that part of the temperature range above $900^{\circ}$ in which no liquid phase appears the integrated form of the van't Hoff equation

$$
2.303 \log _{10} p(\mathrm{~mm} .)=-\frac{\Delta H_{1}}{R T}+\text { const. }
$$

may be directly applied.

Solving for the constants of this equation, applying the method of least: squares to the data of Table IX, we obtain

$$
\log _{10} p(\mathrm{mmm} .)=\frac{-13216}{T}+12.35
$$

as the equation connecting the dissociation pressure of cupric oxide with the absolute temperature for the range $900^{\circ}$ to $1082^{\circ}$ (the eutectic point).

From this we calculate

$$
\Delta H_{1}=60,568 \text { calories }
$$

for the change

$$
{ }_{4} \mathrm{CuO}(\mathrm{s}) \rightarrow 2 \mathrm{Cu}_{2} \mathrm{O}(\mathrm{s})+\mathrm{O}_{2}(\mathrm{~g})
$$

ur"

$$
\left(\Delta H_{1000^{\circ}}\right): \mathrm{CuO}(\mathrm{s}) \longrightarrow 1 / 2 \mathrm{Cu}_{2} \mathrm{O}(\mathrm{s})+{ }^{2} /{ }_{4} \mathrm{O}_{2}(\mathrm{~g})-\mathrm{I}_{5,142} \mathrm{cal}
$$

Previously determined values for the last quantity are $x 7,500$ calories, ${ }^{1}$ I 8,100 calories, ${ }^{2}$ and 16,755 calories. $^{3}$

Again for the change:

$$
{ }_{4} \mathrm{CuO}(\mathrm{s}) \rightleftarrows 2 \mathrm{Cu}_{2} \mathrm{O}(\mathrm{s})+\mathrm{O}_{2}(\mathrm{~g} \text { I atm. })
$$

the corresponding free energy decrease is

$$
-\Delta F=2.303 R T \log _{10} \frac{p(\mathrm{~mm} .)}{760}=-60568+43.38 T .
$$

In making the foregoing calculations, only data lying between $900^{\circ}$ and the eutectic point have been used. A reference to Fig. 7 will show that the first point of Table IX with a pressure of $4.62 \mathrm{~mm}$. at $838.8^{\circ}$, is not in agreement with the rest of the data, and shows too high a pressure value. It is thought that the pressure data at this low temperature are unreliable both because of the fact that small amounts of adsorbed gases cause a large percentage error in pressure readings, and because equilibrium is obtained very much more slowly as the temperature drops below $900^{\circ}$. For these reasons we believe better values of equilibrium pressures at low temperatures may be obtained by extrapolation of the logarithmic curve than by direct measurement.

\section{Summary of Results.}

1. It has been shown that solid solution of cuprous oxide in cupric oxide does not take place in the temperature range where both oxides

1. Dulong, Compt. rend, 7,87 I (1838).

Andrews, Phil. Mag. [3], 32, 32 I (1848).

"J. Thomsen, "Thermochemistry," I908, p. 268. 
remain solid. Previous results indicating such solution may probably be explained by lack of careful temperature control, and by possible adsorption of nitrogen in solid cupric oxide giving high initial pressures. Results below the eutectic point are in agreement with those of Foote and Smith. ${ }^{1}$

2. The pressure-temperature equilibrium curves for the system $\mathrm{CuO}$, $\mathrm{Cu}_{2} \mathrm{O}, \mathrm{O}_{2}$ have been established over the range ( $\mathrm{I}$ ), in which the oxides remain solid, below the eutectic point, and (2) above the eutectic point where cupric oxide remains the solid phase, up to $1233^{\circ}$.

3. The pressure and temperature of the quadruple (eutectic) point for the system have been established from the intersection of these 2 curves. The quadruple point lies at $1080.2^{\circ}$ and $390 \mathrm{~mm}$. pressure.

4. The general direction of the equilibrium curve has been indicated for the system when cuprous oxide remains the only solid phase, and it has been proved that, in accordance with theory, the equilibrium pressure drops in this case with rise in temperature.

5. It has been shown that pure cupric oxide does not melt without dissociation below $1233^{\circ}$.

The foregoing investigation. was begun by one of us at the Research Laboratory of Physical Chemistry of the Massachusetts Institute of Technology. The work was interrupted at the declaration of war and has been continued in this Laboratory.

WAsgrnatoN, D. C.

\section{THE DIELECTRIC CONSTANT OF SELENIUM OXYCHLORIDE.}

BY JAMES E. WILDISH.

Received Ontober 16, 1920.

Selenitum oxychloride was prepared by bringing together molecular proportions of selenium dioxide and selenium tetrachloride. The dioxide was prepared according to Lenher. ${ }^{2}$ The selenium tetrachloride was prepared in the usual manner by treating selenium with an excess of dry chlorine. This was accomplished by allowing finely powdered selenium ${ }^{3}$ to fall through an atmosphere of dry chlorine. The operation was carried out in the apparatus shown in Fig. I. A glass tube, A, about $45 \mathrm{~cm}$. long and $38 \mathrm{~mm}$. in diameter, was tightly fitted into a 4 -liter flask, B. A glass tube, $\mathrm{C}$, about $25 \mathrm{~mm}$. in dianteter and $9 \mathrm{I} \mathrm{cm}$. long, was tightly fitted into Tube $A$. The whole apparatus was made perpendicular by suspending a small weight from the center of the top of the tube. The dry chlorine was passed in at $D$, until the whole apparatus was filled with

${ }^{1}$ Loc. cii.

"Lenher, Turs Journal, 20, 555 (1898).

3 The selenium used in this work was obtained through the courtesy of the Baltimore Copper Smelting and Refining Company. 